\title{
Difficulties With Goals of the Dutch ICF Activity Inventory: Perceptions of Those With Retinitis Pigmentosa and of Those Who Support Them
}

\author{
Keziah Latham, ${ }^{1,2}$ Mohammad Baranian,, ${ }^{2,3}$ Matthew A. Timmis, ${ }^{2,3}$ and Shahina Pardhan ${ }^{2}$ \\ ${ }^{1}$ Visual Function \& Physiology Research Group, Anglia Ruskin University, Cambridge, United Kingdom \\ ${ }^{2}$ Vision \& Eye Research Unit, Postgraduate Medical Institute, Anglia Ruskin University, Cambridge, United Kingdom \\ ${ }^{3}$ Sport \& Exercise Sciences Research Group, Anglia Ruskin University, Cambridge, United Kingdom
}

Correspondence: Keziah Latham, Department of Vision \& Hearing Sciences, Anglia Ruskin University, East Road, Cambridge CB1 1PT, UK; Keziah.latham@anglia.ac.uk.

Submitted: December 10, 2014 Accepted: March 4, 2015

Citation: Latham K, Baranian M, Timmis MA, Pardhan S. Difficulties with goals of the Dutch ICF activity inventory: perceptions of those with retinitis pigmentosa and of those who support them. Invest Ophthalmol Vis Sci. 2015;56:2381-2391. DOI:10.1167/ iovs.14-16237
Purpose. To provide a comprehensive overview of the perceived difficulties with visual activities and participation by those with retinitis pigmentosa (RP), and as perceived by those who support people with RP. Further, to examine the performance of the Dutch ICF Activity Inventory (D-AI) using Rasch analysis.

Methods. Three hundred fifty people with RP and 75 supporters of people with RP provided demographic information and completed the D-AI at goal level ( 47 goals).

Results. Following removal of four goals, the D-AI behaved well in Rasch analysis, but with limitations to its unidimensionality. The most difficult goals for people with RP related to mobility and to work-related activities. Greater difficulty was associated with higher visual impairment registration status, use of mobility aids, and longer duration of visual impairment. For those with less severe visual loss, goals relating to communicating with people were relatively more difficult. In more severe loss, goals involving good central vision (e.g., dealing with correspondence) were relatively more difficult. The perceptions of supporters matched those of the people with RP relatively well, but with a tendency for supporters to overestimate the difficulty of goals, which related to administration and domestic chores, and to underestimate difficulty with goals relating to communication with people.

Conclusions. The results indicate important areas of rehabilitation to address in addition to orientation and mobility in those with RP, including work-related activities and goals involving good central vision. Both people with RP and those supporting them could benefit from help addressing difficulties with communication.

Keywords: patient reported outcome measure, Rasch analysis, caregiver, activities of daily living, retinitis pigmentosa
$\mathrm{Q}$ uestionnaires are increasingly used to assess how difficult people with impaired vision find different activities of daily living (ADLs) due to their visual loss. Such questionnaires can be used to plan individuals' rehabilitation needs, ${ }^{1,2}$ or as outcome measures to determine the effect of interventions. ${ }^{3}$ There are a range of questionnaires, or instruments, available to assess difficulty with ADLs. ${ }^{4,5}$ Massof's Activity Inventory ${ }^{6}$ was the original adaptive questionnaire developed to assess the rehabilitation needs of visually impaired patients from the patient's perspective and to provide an estimate of a visually impaired person's visual ability. The hierarchical structure of this instrument consists of three objectives (daily living, social interactions, and recreation) under which lie 50 goals. For goals that are of at least some importance and some difficulty, the difficulty of tasks underpinning these goals are assessed. There are 459 tasks in total, but only an appropriate selection will be asked of any given respondent.

The Dutch ICF Activity Inventory (D-AI) ${ }^{7,8}$ was designed to extend the preexisting Activity Inventory ${ }^{6}$ in a European context, and is structured such that the goals are classified by the nine 'Activity and Participation' domains of the International Classification of Functioning, Disability and Health ${ }^{9}$ plus an additional domain of 'emotional health.' Compared with the AI, more goals have been added in the areas of mobility, employment, education, and interpersonal interactions, and some goals relating to specific hobbies have been removed. ${ }^{10}$ To identify priority goals for rehabilitation, the importance of a goal is first rated, and for goals with at least some importance, the difficulty is then rated. More importance and greater difficulty are given higher scores, such that the product of the importance and difficulty scores gives a 'priority score,' with higher values having more priority. To keep administration manageable, task difficulty is then assessed only for the 15 goals with the highest priority scores. The D-AI is used to determine rehabilitation needs on a routine basis in the Netherlands. ${ }^{2,10}$ To date, its psychometric properties have only been validated using classical test theory, ${ }^{10}$ but further understanding of the psychometric properties of the instrument can be achieved using Rasch analysis. ${ }^{4,5}$ Such analysis can comment on the extent to which the instrument reflects a single, or unidimensional, construct, although an instrument intended to cover a full range of rehabilitation needs such as the AI or D-AI is unlikely to be completely unidimensional. ${ }^{6,11}$ However, Rasch analysis also allows evaluation of other dimensions of structural 
integrity of the instrument such as the performance of the response scale and the reliability of results. ${ }^{4,5}$

Retinitis pigmentosa (RP) is an inherited condition with a variety of genotypes causing bilateral retinal dystrophy. ${ }^{12}$ It affects approximately 1 in 3500 people in the United States and Europe,${ }^{13}$ and has an age of onset from infancy to early middle age. ${ }^{14}$ The visual impairments leading from RP typically include impaired scotopic vision, followed by restricted visual field, and in the later stages reduced visual acuity (VA), contrast sensitivity, and color vision. ${ }^{15}$ Progression and severity of visual impairment depend to some extent on genotype. ${ }^{12}$

The visual impairments of RP give rise to difficulties with both activities and participation. Given the loss of peripheral visual field, mobility is certainly difficult, ${ }^{16-21}$ but difficulties go beyond this one area. Peripheral detection, ${ }^{20}$ visual search, ${ }^{16}$ reading, ${ }^{20,22}$ and mental health ${ }^{21,23,24}$ have all been found to be affected when assessed. However, most studies have examined the effect of RP on one area of difficulty, or have looked at overall visual difficulty using instruments such as the National Eye Institute 25 item Visual Function Questionnaire (NEI-VFQ 25). ${ }^{21,23,25-28}$ To date, research has not compared the relative difficulties of a comprehensive range of activities to determine the most difficult areas for people with RP, nor considered whether difficulty varies at different stages of the disease. Such research would be useful in identifying likely rehabilitation needs generally across the RP population and also at different stages of the disease. ${ }^{19}$

Support from friends and family for those with visual impairment is valuable both practically ${ }^{29,30}$ and emotional1y. ${ }^{31-33}$ However, previous evidence suggests that over-protection from supporters who underestimate a visually impaired person's capabilities can lead to loss of autonomy and independence, ${ }^{34,35}$ and to reduced quality of life. ${ }^{36,37}$ Providing support to a visually impaired person can also adversely affect supporters' well-being. ${ }^{38,39}$ It is therefore important to understand whether there are differences in the perceptions of difficulty between people with RP and those who support them, which might lead to supporters providing more or less support than the visually impaired person desires or requires, and lead to poorer outcomes for all parties.

The purpose of this study was to provide a comprehensive overview of self-reported difficulties with visual activity and participation goals in RP, both from the perspective of those who have RP, and from the perspective of those who support these people ('supporters'). Integral to this is an examination of the performance of the D-AI using Rasch analysis, as an important extension ${ }^{4,5}$ of the classical validation already done.

\section{MeTHODS}

\section{Participants}

Participants were recruited by advertising the study through the Retinitis Pigmentosa Fighting Blindness (RPFB) Web site, newsletter, and social media pages, and through presence at the annual RPFB conference. Potential participants were provided with the internet address of the online questionnaire, and contact details of the researchers for further information and/or access to the study through different formats. Participants self-reported either that they had RP, or that they provided support for someone with RP. Participants under 18 years of age or supporting someone under 18 years of age were excluded, as were those with coexisting mobility dysfunction in addition to RP. Ethical approval was received from Anglia Ruskin University (Cambridge, UK), and the tenets of the Declaration of Helsinki were upheld. All participants gave their informed consent to take part, once the nature of the study had been explained.

\section{Procedures}

The D-AI ${ }^{10,40}$ was used to investigate, which activity and participation goals were difficult to complete due to vision, assessing the difficulty of 47 rehabilitation goals of the Dutch ICF Activity Screener ${ }^{40}$ nested within 10 domains of the WHOICF framework (Table 1). The wording of these goals was not an official back translation of the Dutch instrument, but used the English phraseology provided by the instrument's author. As an example, the question that is referred to in the following results as 'mobility outdoors' was phrased in full as follows: 'Is mobility outdoors difficult for you because of your visual impairment? Consider how difficult this is to do without the assistance of another person, but with any assistive devices that you use.' Likert scales were used and responses were scored from 0 to 5 , where 0 is 'not applicable/important', 1 is 'impossible to achieve without support,' 2 is 'extreme difficulty,' 3 is 'moderate difficulty, 4 is 'slight difficulty', and 5 is 'no difficulty.' The option of a zero score to indicate that a goal was 'not applicable or not important' was used to simplify administration, instead of asking about goal importance and goal difficulty in separate questions as in the original D-AI. Scores of zero were considered as missing data. The scale of difficulty from 1 to 5 with higher numbers indicating less difficulty was the opposite way around from the original D-AI, where higher scores indicated greater difficulty. The presented scoring system was chosen so that higher person measures from Rasch analysis would indicate higher ability.

In addition, information about the participants' age, sex, duration of visual impairment, use of mobility aids, and visual impairment registration status was ascertained. In the UK, people can be registered as sight impaired with full visual field and VA $3 / 60$ to $6 / 60$, VA up to $6 / 24$ with a 'moderately contracted' visual field, or VA $6 / 18$ or better if there is a 'gross' field defect. Severely sight impaired registration is available to those with VA less than $3 / 60$ and full visual field, VA between $3 / 60$ and $6 / 60$ with a 'significantly contracted' field of vision, or VA of greater than $6 / 60$ with a 'severely contracted' field of vision. ${ }^{41}$ It should be noted however, that interpretation of these guidelines with respect to field loss is not consistent. ${ }^{42}$

Participants completed the questionnaire either online, in print (standard or large print sizes available), or by telephone.

\section{Analysis}

Rasch analysis for the RP participants was undertaken using Winsteps version 3.80.1. ${ }^{43}$ Rasch analysis is a probabilistic measurement model used to construct a linear measure from ordinal observations, ${ }^{44}$ which allows both application of parametric statistics to responses, and detailed evaluation of questionnaire performance. ${ }^{4}$ Responses of 1 to 5 ('impossible without assistance' to 'not difficult') were considered as valid codes and 0 ('not important/not applicable') was considered as missing data. Person and item measures are produced in logits, or log odds units, which represent the likelihood of a person having the ability to achieve an item, or an item being achievable for a person. The average logit value for both persons and items is arbitrarily set to zero. A higher positive person measure indicates that an individual perceives that they have greater ability with the items, and a higher item measure indicates that an individual would need greater ability in order to achieve the task, therefore representing a 'harder' item.

Rasch analysis of the instrument was undertaken with a single Andrich rating scale model. ${ }^{45}$ Initially, category thresholds were examined to determine if all categories were used, 
TABLE 1. Item Characteristics of D-AI Goals

\begin{tabular}{|c|c|c|c|c|c|c|c|}
\hline Item Code & Goal & Domain & $\begin{array}{l}\text { Item } \\
\text { Difficulty, } \\
\text { Logits }\end{array}$ & SE & $\begin{array}{l}\text { Infit } \\
\text { mnsq }\end{array}$ & $\begin{array}{l}\text { Outfit } \\
\text { mnsq }\end{array}$ & $\begin{array}{l}\text { Applicability } \\
\text { (Number of } \\
\text { Nonzero } \\
\text { Responses) }\end{array}$ \\
\hline 403 & Mobility outdoors & Mobility & 1.12 & 0.06 & 0.80 & 0.89 & 349 \\
\hline 606 & Shopping & Domestic life & 0.92 & 0.06 & 0.76 & 0.75 & 343 \\
\hline 906 & Physical activity and/or sport & Community, social and civil life & 0.91 & 0.07 & 1.31 & 1.31 & 319 \\
\hline 402 & Mobility indoors & Mobility & 0.86 & 0.06 & 0.80 & 0.85 & 348 \\
\hline 406 & Using public transport & Mobility & 0.82 & 0.06 & 0.79 & 0.82 & 341 \\
\hline 605 & Grocery shopping & Domestic life & 0.81 & 0.07 & 0.89 & 0.86 & 332 \\
\hline 905 & Holidays and trips & Community, social and civil life & 0.81 & 0.06 & 0.95 & 1.02 & 336 \\
\hline 804 & Applying for a job & Major life areas & 0.79 & 0.09 & 0.91 & 0.88 & 165 \\
\hline 806 & $\begin{array}{l}\text { Accessibility at work, such as } \\
\text { moving around and using } \\
\text { facilities }\end{array}$ & Major life areas & 0.73 & 0.08 & 0.66 & 0.68 & 195 \\
\hline 805 & Working activities & Major life areas & 0.70 & 0.08 & 0.64 & 0.65 & 199 \\
\hline 903 & Social events & Community, social and civil life & 0.66 & 0.06 & 1.14 & 1.18 & 343 \\
\hline 603 & $\begin{array}{l}\text { Doing general maintenance tasks } \\
\text { at home }\end{array}$ & Domestic life & 0.65 & 0.07 & 0.83 & 0.80 & 329 \\
\hline 904 & Dining out & Community, social and civil life & 0.60 & 0.06 & 1.11 & 1.28 & 347 \\
\hline 101 & Reading & Learning and applying knowledge & 0.56 & 0.06 & 0.95 & 0.95 & 343 \\
\hline 907 & $\begin{array}{l}\text { Recreational / leisure time } \\
\text { activities }\end{array}$ & Community, social and civil life & 0.52 & 0.06 & 0.97 & 1.04 & 335 \\
\hline 201 & $\begin{array}{l}\text { Personal administration, such as } \\
\text { dealing with forms and mail }\end{array}$ & General tasks and demands & 0.48 & 0.06 & 1.07 & 1.02 & 345 \\
\hline 801 & $\begin{array}{l}\text { Managing finances, such as } \\
\text { reading accounts or filling in a } \\
\text { form }\end{array}$ & Major life areas & 0.39 & 0.06 & 0.99 & 0.92 & 345 \\
\hline 704 & Interaction with strangers & $\begin{array}{l}\text { Interpersonal interactions and } \\
\text { relationships }\end{array}$ & 0.33 & 0.06 & 1.07 & 1.06 & 347 \\
\hline 608 & Health care for another adult & Domestic life & 0.29 & 0.08 & 1.06 & 0.99 & 199 \\
\hline 609 & (Grand) child care & Domestic life & 0.22 & 0.09 & 1.15 & 1.10 & 180 \\
\hline 803 & Participating in Education & Major life areas & 0.16 & 0.08 & 0.85 & 0.79 & 212 \\
\hline 604 & Withdrawing money and paying & Domestic life & 0.14 & 0.06 & 1.09 & 0.99 & 343 \\
\hline 302 & $\begin{array}{l}\text { Dealing with personal } \\
\text { correspondence }\end{array}$ & Communication & 0.12 & 0.06 & 0.97 & 0.90 & 342 \\
\hline 103 & Watching TV & Learning and applying knowledge & 0.10 & 0.06 & 1.02 & 1.08 & 341 \\
\hline 202 & $\begin{array}{l}\text { Following a schedule and getting } \\
\text { to appointments on time }\end{array}$ & General tasks and demands & 0.05 & 0.06 & 1.33 & 1.31 & 349 \\
\hline 102 & Writing & Learning and applying knowledge & 0.04 & 0.06 & 1.26 & 1.17 & 344 \\
\hline 301 & Using a computer & Communication & -0.01 & 0.07 & 1.00 & 0.97 & 326 \\
\hline 601 & Cleaning and tidying up & Domestic life & -0.04 & 0.06 & 0.76 & 0.77 & 344 \\
\hline 607 & Prepare your usual daily meals & Domestic life & -0.27 & 0.07 & 0.78 & 0.74 & 339 \\
\hline 503 & $\begin{array}{l}\text { Personal health care and } \\
\text { medication }\end{array}$ & Self care & -0.29 & 0.07 & 1.16 & 1.02 & 342 \\
\hline 802 & Getting information & Major life areas & -0.31 & 0.07 & 1.09 & 1.09 & 346 \\
\hline 703 & Interaction with colleagues & $\begin{array}{l}\text { Interpersonal interactions and } \\
\text { relationships }\end{array}$ & -0.39 & 0.07 & 1.25 & 1.19 & 290 \\
\hline 501 & Dressing & Self care & -0.40 & 0.07 & 1.05 & 1.09 & 346 \\
\hline 610 & Pet care & Domestic life & -0.61 & 0.09 & 0.88 & 0.85 & 197 \\
\hline 602 & Doing laundry & Domestic life & -0.63 & 0.07 & 0.95 & 0.85 & 325 \\
\hline 701 & $\begin{array}{l}\text { Communicating with people face } \\
\text { to face }\end{array}$ & $\begin{array}{l}\text { Interpersonal interactions and } \\
\text { relationships }\end{array}$ & -0.72 & 0.07 & 1.25 & 1.26 & 350 \\
\hline 401 & Mobility at home & Mobility & -1.01 & 0.07 & 0.82 & 0.97 & 347 \\
\hline 902 & Having visitors & Community, social and civil life & -1.09 & 0.07 & 0.97 & 0.90 & 344 \\
\hline 504 & Eating and drinking & Self care & -1.27 & 0.08 & 0.86 & 0.77 & 342 \\
\hline 702 & Relationship with loved ones & $\begin{array}{l}\text { Interpersonal interactions and } \\
\text { relationships }\end{array}$ & -1.33 & 0.08 & 1.09 & 1.19 & 335 \\
\hline 303 & Using a telephone & Communication & -1.46 & 0.08 & 1.12 & 1.38 & 348 \\
\hline 901 & Following the news & Community, social and civil life & -1.93 & 0.09 & 1.03 & 0.82 & 349 \\
\hline 502 & Personal hygiene & Self care & -1.99 & 0.09 & 1.07 & 1.00 & 342 \\
\hline
\end{tabular}

Item difficulty and standard error (SE) of goals, in logits, are shown in difficulty order from most to least difficult. The domain that the goal underlies and the number of valid responses (maximum 350) indicating the general relevance of the question to the sample is also shown, as are mean square (mnsq) infit and outfit. Item codes are used for brevity to identify goals in Figure. 
that categories were used in order of functional ability, and that each category was the most probable response at some point on the ability scale. The fit of items to a unidimensional construct was then assessed, with acceptable fit defined as infit and outfit values within a range of 0.6 to $1.4 .{ }^{46}$ Any ill-fitting goals were removed iteratively, with the most misfitting removed first and the analysis repeated until all item fits were within the specified range.

The reliability indices of the resulting instrument were assessed in terms of person separation statistics, which provide an indication of the instrument's ability to discriminate between respondents: person separation and person reliability should be greater than the suggested minima of 2.0 and 0.80 , respectively. ${ }^{43,47}$ Further, item separation statistics provide an indication of how reliably ordered the items are in terms of difficulty: item separation and item reliability should be in excess of suggested minima of 3.0 and $0.90 .{ }^{43}$ Targeting, or the difference between mean item and person measures, should ideally be less than 1.0 logit. ${ }^{47}$

Further assessment of the unidimensionality of the instrument is important to demonstrate the extent to which an instrument assesses a single latent trait. In Rasch residual-based principal components analysis (PCA), the variance in the data that is accounted for by the Rasch dimension is first considered, with at least $60 \%$ of variance explained by the primary measure considered to demonstrate reasonable overall unidimensionality ${ }^{47,48}$ in the instrument. The unexplained variance, or residuals, are then decomposed to look for patterns that may indicate a secondary dimension to the data rather than random noise. For potential additional dimensions to be considered, the contrast found within the residuals after the primary model has been extracted has to have at least the strength of two items (i.e., an eigenvalue of at least 2.0, because this is close to that seen within random data). ${ }^{43}$

\section{Results}

\section{Participants}

Three hundred fifty people with RP (184 females, 166 males, age $55 \pm 15$ years) completed the D-Al. The D-AI was completed online by 278 participants, by phone by 45 , and in print by 27 . Twenty-six participants were not registered as visually impaired, 110 were sight impaired, and 214 severely sight impaired. A guide dog and/or cane were used by 194 participants to aid mobility, and 156 used no mobility aids.

Seventy-five people who care or provide support for someone aged 18 years or over with RP also completed the D-AI to give their own view of how difficult their person with RP found different activities. Of these, 63 carers completed the $\mathrm{D}-\mathrm{AI}$ online, one by phone, and 11 in print. Of the 75 people with RP that were described by their supporters, there were 33 females and 42 males, of mean age $56 \pm 15$ years. Five of the people with RP being supported were not registered as visually impaired, 17 were registered as sight impaired, and 53 were severely sight impaired. Supporters reported a guide dog and/ or cane were used by 44 people with RP, and no mobility aids by 31 people with RP. As responses were collected anonymously, it was not possible to relate the responses of a supporter to those of the specific person with RP that they supported.

\section{Rasch Analysis}

Rasch-Andrich thresholds, indicating the point on the scale where the category below was equally probable to that specified, were none, $-1.51,-0.60,0.53$, and 1.57 logits for categories 1 to 5 respectively. Categories were thus ordered, all categories were used and each was the most probable response at some point on the ability scale. In the initial analysis of all 47 goals, not all items fitted well to the unidimensional construct. Four goals were iteratively removed for this sample due to underfit: driving a car, riding a bicycle, emotional life, and acceptance of visual loss, and coping with fatigue and balancing energy levels.

The resulting 43 item instrument then showed good reliability indices as shown in Table 1 . Person separation of 4.50 and person reliability of 0.95 indicate that the instrument is capable of reliably classifying participants into four ability groups. ${ }^{43}$ Item separation was 10.65 , and item reliability 0.99 . Targeting was $0.70 \pm 1.43$ logits.

Principal component analysis of residuals demonstrated that the instrument showed reasonable overall unidimensionality ${ }^{47,48}$ with $60 \%$ of variance explained by the primary measure. Additionally, the raw variance explained by the items in the principal Rasch analysis (19\%) was three times greater than the unexplained variance in the first contrast $(6.4 \%)$, showing that although there is a noticeable second dimension, it accounts for far less of the variation in the data than does the primary Rasch dimension. ${ }^{49}$

Evaluation of the PCA contrasts between opposing factors indicated that there were seven items in the first contrast (eigenvalue 6.8), related to tasks requiring fine central visual function $(201,801,302,102,604,101,103$ : see Table 1 for item descriptions). The second contrast (eigenvalue 3.1) included items related to outdoor orientation and mobility (406, 606, 403). The third contrast (eigenvalue 2.7) included the items in the 'learning and applying knowledge' domain $(101,102,103)$. The final contrast with strength of more than 2 Eigen units (2.1) included items relating to work $(805,804)$. Person measures for the questions in the first contrast were compared with person measures for all other questions. ${ }^{49}$ The correlation between these person measures was 0.80 , such that $64 \%$ of the variance in one person measure was explained by the other. Examination of the correlation plot indicated that the participants whose person measures did not correlate well were those who had no difficulty (maximum person measure, or ceiling effect) with the questions in the first contrast, but did have difficulties in the other areas assessed in the remaining questions. Given that the purpose of the study is to compare areas of difficulty across a range of rehabilitative needs and levels of difficulty, the instrument was left intact at this level in this instance.

\section{Difficulty of Goals for People With RP}

Item difficulties for individual goals ranged from 1.12 logits (mobility outdoors; most difficult) to -1.99 logits (personal hygiene; least difficult) and are shown in Table 1, and in the person-item map (Fig.), which also demonstrates the range and targeting of the instrument.

To determine which of the demographic factors assessed influenced goal difficulty as assessed by the D-AI, person measures for different participant characteristics were compared using person subgroup totals (Table 2). Comparing responses by visual impairment registration status, ability was not significantly different (mean difference 0.62 logits, Welch 2-sided $t$-test, $t=1.67, d f=32, P=0.106$ ) between those not registered and those registered as sight impaired (SI), whereas both groups differed significantly from those registered as severely sight impaired (SSI; nonregistered: mean difference 2.08, $t=5.88, d f=26, P=0.000$; sight impaired: mean difference $1.46, t=9.80, d f=168, P=0.000$ ). The data was therefore recoded as less impaired (not registered and SI) or SSI (Table 2). The difference between these two groups in terms of 
TABLE 2. Person Measures for RP Participants

\begin{tabular}{lccccccl}
\hline $\begin{array}{c}\text { Number of } \\
\text { Participants }\end{array}$ & $\begin{array}{c}\text { Mean } \\
\text { Person } \\
\text { Measure }\end{array}$ & SE Mean & Observed SD & Median & Model Separation & Model Reliability & \multicolumn{1}{c}{ Group } \\
\hline 350 & 0.70 & 0.08 & 1.43 & 0.57 & 4.74 & 0.96 & All \\
136 & 1.66 & 0.13 & 1.47 & 1.37 & 3.50 & 0.92 & Registration:SI and not registered \\
214 & 0.08 & 0.07 & 0.99 & 0.05 & 5.01 & 0.96 & Registration:SSI \\
156 & 1.38 & 0.13 & 1.58 & 1.18 & 3.99 & 0.94 & No mobility aids \\
214 & 0.15 & 0.07 & 1.00 & 0.09 & 4.99 & 0.96 & Uses mobility aids \\
170 & 0.88 & 0.10 & 1.31 & 0.85 & 4.97 & 0.96 & Younger age \\
180 & 0.52 & 0.11 & 1.51 & 0.30 & 4.53 & 0.95 & Older age \\
181 & 1.13 & 0.12 & 1.58 & 1.03 & 4.27 & 0.95 & Shorter duration of loss \\
169 & 0.23 & 0.08 & 1.06 & 0.15 & 5.14 & 0.96 & Longer duration of loss \\
\hline
\end{tabular}

The first row gives figures for the group as a whole. The remaining rows show the data split into two groups by registration status, use of mobility aids, age (median split at 55 years) and duration of vision loss (median split at 24 years). Statistics given for each group represent the mean and median person measures and their variability (higher person measure values indicate greater perceived ability with the goals). Model separation and reliability indicate how reliably ordered the participants are within these subsets, and values are greater than the suggested minima (see text for details) for all subsets.

person measure was significant (mean difference 1.58 logits, $t$ $=10.94, d f=212, P=0.000$ ), indicating that those less impaired had significantly more perceived ability than those registered as SSI. Participants who do not use mobility aids reported greater ability than those who use a mobility cane and/or guide dog (mean difference 1.23 logits, $t=8.45, d f=$ $251, P=0.000)$. Younger participants ( $<55$ years: median split) reported slightly greater ability than older participants $(\geq 55$ years; mean difference 0.36 logits, $t=2.35, d f=345, P=$ 0.019). Participants having had RP for less time ( $\leq 24$ years: median split) reported greater ability than those with more longstanding RP ( $>24$ years; mean difference 0.91 logits, $t=$ $6.33, d f=316, P=0.000)$. There was no difference in reported ability by sex (mean difference -0.15 logits, $t=-0.99, d f=342$, $P=0.325$ ).

Multiple regression analysis of the principal factors identified that influence person measures was undertaken by the forward method, adding registration status, use of mobility aids, duration of visual impairment, and age to the model in turn. Difficulty with activity and participation goals as described by the overall person measure were most influenced by registration status, accounting for $29 \%$ of the variance $\left(R^{2}\right)$ in the data, with increasing severity of visual impairment reflected in higher goal difficulty. Additional significant factors associated with greater difficulty were the use of mobility aids $\left(R^{2}\right.$ change $\left.4 \%\right)$ and longer duration of visual impairment $\left(R^{2}\right.$ change $2 \%$ ). Together these factors accounted for $35 \%$ of the variance. Age was not associated with goal difficulty. The variation inflation factor was sufficiently low for all variables $(<1.5)$ indicating absence of bias from multicollinearity. The standardized residuals supported adequate fit of the sample to the model, with no evidence of cases unduly influencing the model (maximum Cook's distance 0.04, and Mahalanobis distance 6.4).

\section{Differences in Perceived Ability for Individual Goals}

Having identified that registration status, use of mobility aids and duration of visual loss are factors that impact on difficulty of activity and participation goals overall, are the differences observed the same across all items, or are the differences more marked for some items than others? To examine this question, uniform differential item functioning (DIF) or item bias was assessed, which tests the assumption that an item has the same amount of extra difficulty for all those in one classification group. The difference in difficulty of the item between two groups is given by the DIF contrast, and should be at least 0.5 logits for DIF to be noticeable. ${ }^{43}$ Additionally, a statistically significant probability value shows that there is little likelihood of observing this amount of contrast by chance, when there is no systematic item bias effect, ${ }^{43}$ and here $P$ less than 0.01 was considered significant.

Table 3 shows items with significant (logit contrasts $>0.5$, $P<0.01$ ) DIF by visual impairment status (SI and not registered versus SSI). No values were greater than 1.0 logit, ${ }^{47}$ which might damage the integrity of the scale and merit action in terms of splitting the item or removing it. ${ }^{43}$ The goals that were harder for those registered SSI tend to relate to specific tasks involving fine central vision, such as writing or form filling, and five of these nine goals were also included in the first contrast identified in initial analysis. There were also goals that were relatively more difficult for those with less impairment: these were items that generally had lower baseline item difficulties ('easier' goals: see Table 1), and largely relate to communicating with people.

Considering DIF by use of mobility aids, only 'dealing with personal correspondence' (302) was significantly more difficult $(-0.52$ logits) for those who use mobility aids. 'Mobility at home' (401) was significantly more difficult (0.52 logits) for those who do not use mobility aids. In terms of duration of visual impairment, DIF was only significant for the item 'interaction with strangers' (704), which was 0.73 logits harder for those who had been visually impaired for less than the median (24 years) time.

\section{Difficulty of Goals for People With RP: Perceptions of Supporters}

There were no significant differences in the composition of the sample with RP described by their supporters as opposed to the sample with RP (Table 4).

The responses of supporters are presented in Table 5 anchored to the item difficulties determined for those with RP, in order to put the supporters' responses in the same measurement frame of reference. ${ }^{43}$ The displacement, or the difference between the item difficulty in logits as anchored and the difficulty that would have been obtained by analyzing the supporters' data in isolation, is presented for each goal. Goals are ordered by the amount of displacement between supporters and patients attitudes. A positive value indicates that the supporters perceived the item to be more difficult than those with RP themselves did, and this tended to be the case for 
TABLE 3. Items Showing Significant DIF for Visual Impairment Registration Status

\begin{tabular}{|c|c|c|c|c|c|}
\hline \multicolumn{3}{|c|}{ Items Harder for Nonregistered/SI } & \multicolumn{3}{|c|}{ Items Harder for SSI } \\
\hline Goal & $\begin{array}{c}\text { DIF } \\
\text { Contrast }\end{array}$ & $\begin{array}{c}\text { SE of } \\
\text { Contrast }\end{array}$ & Goal & $\begin{array}{c}\text { DIF } \\
\text { Contrast }\end{array}$ & $\begin{array}{c}\text { SE of } \\
\text { Contrast }\end{array}$ \\
\hline Interaction with colleagues (703) & 0.96 & 0.15 & Writing (102) & -0.97 & 0.15 \\
\hline Interaction with strangers (704) & 0.83 & 0.13 & $\begin{array}{l}\text { Personal administration, such as dealing } \\
\text { with forms and mail (201) }\end{array}$ & -0.77 & 0.14 \\
\hline $\begin{array}{l}\text { Relationship with loved ones } \\
\quad(702)\end{array}$ & 0.82 & 0.16 & Prepare your usual daily meals (607) & -0.76 & 0.16 \\
\hline $\begin{array}{l}\text { Communicating with people face } \\
\text { to face }(701)\end{array}$ & 0.73 & 0.14 & Withdrawing money and paving (604) & -0.71 & 0.15 \\
\hline Social events (903) & 0.76 & 0.13 & $\begin{array}{l}\text { Managing finances, such as reading } \\
\text { accounts or filling in a form (801) }\end{array}$ & -0.66 & 0.14 \\
\hline Having visitors (902) & 0.70 & 0.16 & $\begin{array}{l}\text { Dealing with personal correspondence } \\
\text { (302) }\end{array}$ & -0.62 & 0.14 \\
\hline Mobility at home (401) & 0.69 & 0.15 & Health care for another adult (608) & -0.54 & 0.19 \\
\hline Dining out (904) & 0.63 & 0.13 & Shopping (606) & -0.52 & 0.13 \\
\hline $\begin{array}{l}\text { Recreational/ leisure time } \\
\text { activities (907) }\end{array}$ & 0.60 & 0.13 & Applying for a job (804) & -0.52 & 0.19 \\
\hline
\end{tabular}

Goals are ordered by size of DIF contrast. Baseline difficulties for each goal are given in Table 1 .

administrative and domestic goals where difficulty could perhaps be more directly observed. A negative value indicates that the supporters perceived less difficulty with the goal than the people with RP did, and tended to be the case for goals relating to communicating with people. There is no relationship between the baseline item difficulty and the amount of displacement $(r=-0.12, P=0.46)$, and the maximum displacement is relatively small, ${ }^{43}$ at 0.51 logits.

\section{Discussion}

The purpose of the study was to provide an overview of difficulties with activity and participation goals for those with $\mathrm{RP}$, investigate differences in the perceptions of difficulty between those with RP and those supporting them, and to validate the D-AI using Rasch analysis.

The seven most difficult goals for people with RP were: mobility outdoors, shopping, physical activity and/or sports, mobility indoors, using public transport, grocery shopping, and holidays and trips. The common theme to these goals is that they all have orientation and mobility aspects to them, although the goals did not all come from the mobility domain of the questionnaire. Provision of, or referral for, orientation and mobility training should therefore be strongly considered for anyone with RP. There is evidence that such training can improve perceived performance in mobility based activities. ${ }^{50,51}$ Within such training it would be important not only to consider mobility goals related to daily living, but also to recreational goals improving access to physical activity or sport and holidays or trips
The remainder of the 'top 10' most difficult goals came from the 'major life areas' domain: applying for a job, accessibility at work such as moving around and using facilities, and working activities. Work-related goals are therefore very difficult for those to whom it is applicable, and these were applicable goals for $47 \%$ to $57 \%$ of the respondents (Table 1). It is known that visually impaired people are much more likely to be unemployed than their sighted peers, ${ }^{52}$ and the present study demonstrates the difficulty that people with RP perceive with gaining and staying in employment. Consideration of the visual needs of those with RP in their work environment should be a key part of low vision rehabilitation, including referral to specialist services (such as in the $\mathrm{UK}^{53}$ ) where necessary.

The factor most heavily influencing perceived difficulty with activity and participation goals was visual registration status. In the absence of formal clinical data, which could not have been obtained in an online survey, registration status is an indicator of the level of visual loss. Worse visual status was the principal factor associated with greater difficulty, as has previously been shown for samples with mixed causes of visual loss ${ }^{54}$ and for those with RP. ${ }^{17,19,21}$

The use of mobility aids was also associated with greater difficulty. Even though participants were specifically asked to rate the difficulty of goals with the use of any assistive devices, this does not mean that the aids did not lessen the difficulty of goals. Eighty-one percent of those using mobility aids were registered as SSI, as opposed to $37 \%$ of those not using mobility aids. Therefore, the use of mobility aids is also suggestive of more advanced disability. It has also been observed (Tabrett et al., IOVS 2012;53:ARVO E-Abstract 5464) that self-reported difficulty tends to better reflect performance under conditions where aids are not used rather than when using any assistive

Table 4. Comparison of the Two Groups of Respondents: Those With RP (RP; $n=350)$, and Those Supporting Someone With RP Regarding the Ability of the Person With RP (Supporters; $n=75$ )

\begin{tabular}{lccl}
\hline & RP & Supported & \\
\hline Sex, \% female & $53 \%$ & $44 \%$ & $\chi^{2}(d f 1)=1.82, P=0.18$ \\
Mean age, y & $55 \pm 15$ & $56 \pm 15$ & Independent $t$-test: $t(d f 423)=0.84, P=0.40$ \\
Registration status, \% SSI & $61 \%$ & $71 \%$ & $\chi^{2}(d f 1)=2.00, P=0.16$ \\
Use of mobility aids, \% yes & $55 \%$ & $59 \%$ & $\chi^{2}(d f 1)=0.26, P=0.61$ \\
\hline
\end{tabular}


TABLE 5. Differences in the Perceptions of Goal Difficulty by Those Caring for Someone With RP Compared With Those With RP

\begin{tabular}{|c|c|c|c|c|c|}
\hline Item Code & Goal & $\begin{array}{l}\text { Displacement, } \\
\text { Logit }\end{array}$ & Model SE & $t$ & $\begin{array}{c}\text { Anchored } \\
\text { Difficulty, Logit }\end{array}$ \\
\hline 102 & Writing & 0.46 & 0.14 & 3.29 & 0.04 \\
\hline 302 & Dealing with personal correspondence & 0.42 & 0.14 & 3.00 & 0.12 \\
\hline 201 & Personal administration, such as dealing with forms and mail & 0.41 & 0.14 & 2.93 & 0.48 \\
\hline 608 & Health care for another adult & 0.38 & 0.17 & 2.24 & 0.29 \\
\hline 603 & Doing general maintenance tasks at home & 0.35 & 0.14 & 2.50 & 0.65 \\
\hline 503 & Personal health care and medication & 0.34 & 0.13 & 2.62 & -0.29 \\
\hline 602 & Doing laundry & 0.33 & 0.14 & 2.36 & -0.63 \\
\hline 802 & Getting information & 0.33 & 0.14 & 2.36 & -0.31 \\
\hline 801 & Managing finances, such as reading accounts or filling in a form & 0.28 & 0.14 & 2.00 & 0.39 \\
\hline 403 & Mobility outdoors & -0.31 & 0.15 & -2.07 & 1.12 \\
\hline 402 & Mobility indoors & -0.38 & 0.14 & -2.71 & 0.86 \\
\hline 905 & Holidays and trips & -0.42 & 0.14 & -3.00 & 0.81 \\
\hline 904 & Dining out & -0.43 & 0.14 & -3.07 & 0.6 \\
\hline 703 & Interaction with colleagues & -0.45 & 0.16 & -2.81 & -0.39 \\
\hline 704 & Interaction with strangers & -0.49 & 0.14 & -3.50 & 0.33 \\
\hline 903 & Social events & -0.49 & 0.14 & -3.50 & 0.66 \\
\hline 702 & Relationship with loved ones & -0.51 & 0.15 & -3.40 & -1.33 \\
\hline
\end{tabular}

Differences in goal difficulty are indicated by the displacement value (logits), with positive values indicating greater difficulty perceived by supporters, and negative values indicating greater difficulty perceived by those with RP. For clarity, only goals for which the displacement has a significant $t$ value $(t> \pm 1.99 ; P<0.05$ for $d f 74)$ are shown; displacements of goals between 801 and 403 were not significant. The difficulty expressed by those with RP (anchored difficulty) is also given for reference.

device, even when difficulty with the use of any aids is requested to be reported. This may account for some of the additional difficulty perceived by those using mobility aids.

Duration of visual loss was also related to self-reported difficulty in this sample of people with RP, and has previously been shown to relate to perceived mobility difficulties in RP. ${ }^{19}$ However, duration of loss was not a significant factor influencing perceived difficulty in a general low-vision sample. ${ }^{54}$ The difference may be that in a mixed low-vision sample, many people may have stable visual loss which is not changing significantly over time, whereas RP is a progressive disease where visual disability could be expected to increase over time.

Item bias (DIF) shows that the goals that are more difficult for those who are registered SSI revolve around administrative and daily chores, highlighting the loss of central visual function such as VA and contrast sensitivity in the later stages of the disease. ${ }^{15}$ Interventions in terms of provision of magnification and contrast enhancement will be particularly relevant to those in the later stages of the disease.

Supporters' perceptions of the difficulties encountered by those with RP were relatively accurate, ${ }^{43}$ in that the maximum displacement between supporters' difficulty rating and that perceived by those with RP was only 0.51 logits. The largest positive displacements (indicating supporters thought the goals were more difficult than the people with RP did) were also for goals requiring central visual functions, such as writing and form filling, followed by household or domestic chores. These are goals that the supporter can observe the person with RP attempting, and perhaps also that the supporter has specific interest in the person with RP being able to achieve. It is possible that with this discrepancy, supporters may offer or provide more help in these areas than is perceived necessary by the person with RP.

DIF also indicates that for those with less severe visual loss due to RP the communication and social aspects related to vision loss are relatively more difficult. These goals may be more difficult for the less impaired because they have not yet adapted to their visual loss as those with more severe impairment have done. It should also be noted that although the two goals from the emotional health domain were removed from analysis as the items lacked unidimensionality with the other goals, these questions were seen as being relatively difficult (median difficulty 3.5 of 5), and in ordinal analysis was the domain of greatest difficulty for those who were not registered as visually impaired. ${ }^{55}$ Thus, it is suggested that support with the emotional and communication aspects of visual loss ${ }^{56,57}$ should be considered early in rehabilitation for those with RP, and may be key in early adjustment to visual loss in this progressive condition. Support programs designed for those with macular degeneration or age-related vision loss have been shown to be effective, ${ }^{58-61}$ but interventions may need to be designed more specifically for participants with progressive conditions such as RP.

For the supporters, the largest negative displacements (indicating that supporters viewed these goals were less difficult than the people with RP reported that they were) were also for social and personal interaction goals. Notably, the goal with greatest negative displacement was that of 'relationship with loved ones.' It is potentially more difficult for supporters to judge how much difficulty there is, or effort that has to be made by a person with RP with goals of this type, as compared with specific observable activities such as 'writing.' It is therefore possible that supporters may offer less assistance or understanding in these areas of personal interaction than would be beneficial to the person with RP.

These findings support suggestions that interventions for those who support visually impaired people may be helpful. ${ }^{39,62,63}$ Such interventions could usefully include discussion of the need for assistance in interpersonal interactions, as the data suggest that supporters tend to underestimate difficulty in these areas, and this is also an area which is specifically more difficult for those in the earlier stages of sight loss (Table 3).

The different administration methods (online, print, or phone) were used in order to give as many individuals as possible access to taking part in the study. However, it is known that differences do arise when questionnaires are administered in different ways. ${ }^{64,65}$ In this study, there were significant differences in registration status between administration modalities $\left(\chi^{2}[d f 2]=21.84, P<0.000\right)$, with those 


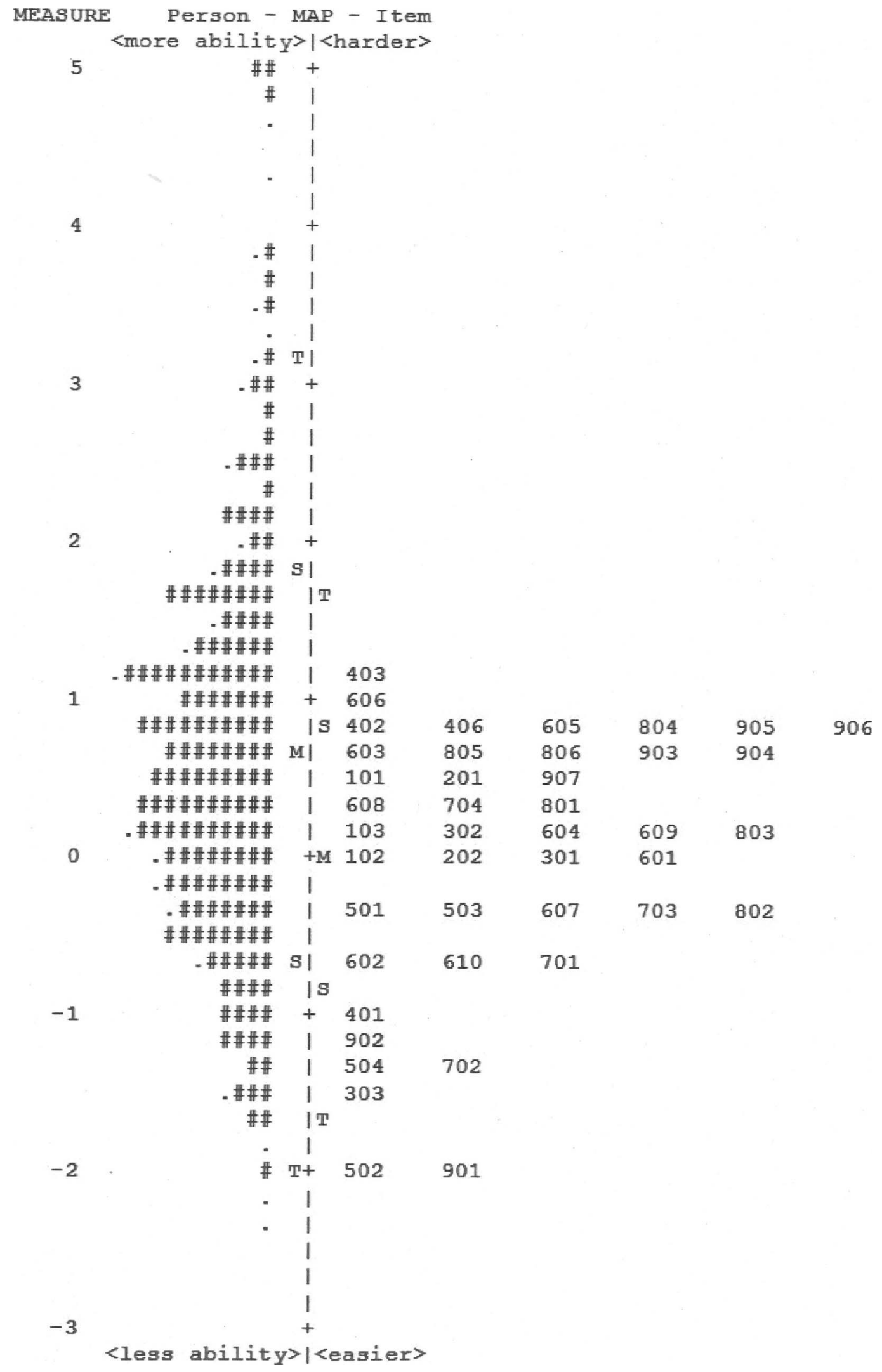

Figure. Person-item map of 43 D-AI goals for the sample of people with RP. For context, an individual who responded 'no difficulty' to every relevant question would have a person measure of approximately 6.8 logits, whereas the equivalent measure for one who responded 'impossible without help' to all relevant questions would be -6.8 logits. $\mathrm{M}=$ mean of the person/item distribution, $\mathrm{S}=1 \mathrm{SD}$ from the person/item mean, $\mathrm{T}=2$ SDs from the person/item mean. The item code reflects the goals as outlined in Table 1 . For persons: \# $=5$ participants, . = 1 participant. 
completing the questionnaire by phone more likely to be registered SSI (91\%) than those who completed in print $(70 \%)$ or online (55\%). Person measures were also significantly different between the groups $(\mathrm{F}[2,347]=13.68, P=0.000)$, with Bonferroni post hoc comparisons indicating a significantly better perceived ability for those completing the questionnaire online as opposed to print $(P=0.001)$ or phone $(P=$ $0.000)$, but no difference between print and phone administrations $(P=1.00)$. It was considered that excluding these participants who used different administration methods would reduce the range of participant experiences examined to a degree that would not be compensated for by the benefits of increasing the homogeneity of the data administration methods.

It should be noted that there were fewer supporter $(n=75)$ than RP responses $(n=350)$, and that because respondents were anonymous it could not be confirmed that the supporters were necessarily responding about people with RP who had also completed the study. However, the demographic profiles of the people described by the RP and supporter samples were statistically similar. Further studies of the differences in ability perceived by visually impaired people and by those who support them, with the ability to directly compare responses regarding the same people, would be valuable to extend the present findings.

For this sample of participants, four misfitting goals were removed from the instrument in Rasch analysis. Two of these goals related to the use of vehicles ('driving a car' and 'riding a bicycle') and caused some confusion to participants, with some interpreting that driving was 'not applicable' because they did not meet visual standards for driving, and some interpreting that driving was 'impossible without help.' Although in the UK there are no visual standards for riding a bicycle, it is suggested that participants viewed the bicycle question in the same way. The other two items removed related to the emotional health domain, which for this sample did not fit the unidimensional construct of the remainder of the questions, which were concerned with difficulties in specific activities of daily living.

Having removed these four items, the D-AI showed good person (4.50) and item separation (10.65) and targeting (0.70 \pm 1.43 logits). With good separation values and a large number of respondents across a range of abilities, the present findings can be expected to be reliable for people with RP. However, the instrument may perform differently for other groups, such as those with macular degeneration or a mixed low-vision sample, and these should also be assessed in future studies.

Although all item fits were in the range 0.60 to 1.40 , and the Rasch dimension dominated the proportion of variance explained by the instrument, contrasts were identified in principal component analysis of the Rasch residuals, which might warrant consideration of removing these items into separate instruments. The first contrast related to tasks requiring good central visual function, and was driven by participants potentially in the earlier stages of the disease with as yet unaffected central vision who had no difficulty with these goals yet had difficulty in other areas of the instrument. To remove the questions from the contrasts into separate instruments would improve the unidimensionality, but would limit the ability to determine relative difficulties in activity and participation goals across a range of participant abilities. In a wide-ranging instrument such as the D-AI, which aims to assess a full range of rehabilitation needs, it should not be expected that unidimensionality would be as defined as for some other instruments that address a single specific issue. Indeed, illfitting goals were not removed from the original AI because of the important contribution they made to planning rehabilita- tion, ${ }^{11}$ and the $\mathrm{AI}$ in its entirety has been shown not to be strictly unidimensional, but to represent a composite variable with at least two dimensions, loaded toward reading and mobility. ${ }^{6}$ The unidimensionality of the D-AI was considered to be adequate for the purposes of this study, but if the purpose of the study were different, then removing questions into separate questionnaire(s) might be indicated to improve unidimensionality.

In conclusion, the principal difficulties experienced by people with RP overall relate to mobility and work activities. For those with less severe visual loss, interpersonal interactions are relatively more difficult, and for those with more severe visual loss tasks with demanding central vision requirements become relatively more difficult. Supporters' perceptions of the difficulties that people with RP had were relatively accurate, but they perceived more difficulty with administrative and domestic goals than the people with RP did, and perceived less difficulty with interpersonal interactions. Rasch analysis showed that the D-AI at goal level performs relatively well as an instrument assessing perceived ability with daily living tasks, although as might be expected for a questionnaire aiming to examine a full range of rehabilitation needs, its unidimensionality is not perfect.

\section{Acknowledgments}

The authors thank the members of RP Fighting Blindness (Buckingham, UK) for their enthusiasm for this project, and in particular Sue Drew and David Head.

Disclosure: K. Latham, None; M. Baranian, None; M.A. Timmis, None; S. Pardhan, None

\section{References}

1. Stelmack JA, Massof RW. Using the VA LV VFQ- 48 and LV VFQ20 in low vision rehabilitation. Optom Vis Sci. 2007;84:705709 .

2. Bruijning J, van Nispen R, Knol D, van Rens G. Low vision rehabilitation plans comparing two intake methods. Optom Vis Sci. 2012;89:203-214.

3. Binns AM, Bunce C, Dickinson C, et al. How effective is low vision service provision? A systematic review. Surv Ophthalmol. 2012;57:34-65.

4. Pesudovs K, Burr JM, Harley C, Elliott DB. The development, assessment and selection of questionnaires. Optom Vis Sci. 2007;84:663-674.

5. Khadka J, McAlinden C, Pesudovs K. Quality assessment of ophthalmic questionnaires: review and recommendations. Optom Vis Sci. 2013;90:720-744.

6. Massof RW, Ahmadian L, Grover LL, et al. The Activity Inventory: an adaptive visual function questionnaire. Optom Vis Sci. 2007;84:763-774.

7. Bruijning JE, van Nispen RMA, van Rens GH. Dutch ICF version of the Activity Inventory: results from a pilot study among visually impaired persons. BMC Health Serv Res. 2010; $10: 318$.

8. Bruijning JE, van Nispen RMA, Verstraten PFJ, van Rens GH. Dutch ICF version of the Activity Inventory: results from focus groups with visually impaired persons and experts. Ophthalmic Epidemiol. 2010;17:366-377.

9. World Health Organization. International classification of functioning, disability and health (ICF). 2001. Available at: www.who.int/classifications/icf/en. Accessed November 18, 2014.

10. Bruijning JE, van Rens G, Knol D, van Nispen R. Psychometric analyses to improve the Dutch ICF Activity Inventory. Optom Vis Sci. 2013;90:806-819. 
11. Massof RW, Hsu CT, Baker FH, Barnett GD, Park WL, Deremeik JT, et al. Visual disability variables. I: the importance and difficulty of activity goals for a sample of low-vision patients. Arch Phys Med Rehab. 2005;86:946-953.

12. Fahim AT, Daiger SP, Weleber RG. Retinitis pigmentosa overview Seattle (WA): University of Washington, Seattle: GeneReviews. 1993-2014. Available at: http://www.ncbi.nlm. nih.gov/books/NBK1417/. Accessed November 18, 2014.

13. Haim M. Epidemiology of retinitis pigmentosa in Denmark. Acta Ophthalmol Scand Suppl. 2002;233:1-34.

14. Haim M. Prevalence of retinitis pigmentosa and allied disorders in Denmark. Acta Ophthalmol. 1992;70:417-426.

15. Herse P. Retinitis pigmentosa: visual function and multidisciplinary management. Clin Exp Optom. 2005;88:335-350.

16. Lowe J, Drasdo N. Patients' responses to retinitis pigmentosa. Optom Vis Sci. 1992;69:182-185.

17. Szlyk JP, Fishman GA, Alexander KR, Revelins BI, Derlacki DJ, Anderson RJ. Relationship between difficulty in performing daily activities and clinical measures of visual function in patients with retinitis pigmentosa. Arch Ophthalmol. 1997; 115:53-59.

18. Geruschat DR, Turano KA, Stahl JW. Traditional measures of mobility performance and retinitis pigmentosa. Optom Vis Sci. 1998;75:525-537.

19. Turano KA, Geruschat DR, Stahl JW, Massof RW. Perceived visual ability for independent mobility in persons with retinitis pigmentosa. Invest Ophthalmol Vis Sci. 1999;40:865-877.

20. Szlyk JP, Seiple W, Fishman GA, Alexander KR, Grover S, Mahler CL. Perceived and actual performance of daily tasks: relationship to visual function tests in individuals with retinitis pigmentosa. Ophthalmology. 2001;108:65-75.

21. Sugawara T, Hagiwara A, Hiramatsu A, Ogata K, Mitamura Y, Yamamoto S. Relationship between peripheral visual field loss and vision-related quality of life in patients with retinitis pigmentosa. Eye. 2010;24:535-539.

22. Sandberg MA, Gaudio MR. Reading speed of patients with advanced retinitis pigmentosa or choroideremia. Retina. 2006; 26:80-88.

23. Hahm BJ, Shin YW, Shim EJ, Jeon HJ, Seo JM, Chung H, et al. Depression and the vision-related quality of life in patients with retinitis pigmentosa. BrJ Ophthalmol. 2008;92:650-654.

24. Kim S, Shin DW, An AR, Lee CH, Park JH, Lee HK. Mental health of people with retinitis pigmentosa. Optom Vis Sci. 2013;90:488-493.

25. Burstedt MS, Monestam E, Sandgren O. Associations between specific measures of vision and vision-related quality of life in patients with bothnia dystrophy, a defined type of retinitis pigmentosa. Retina. 2005;25:317-323.

26. Seo JH, Yu HG, Lee BJ. Assessment of functional vision score and vision-specific quality of life in individuals with retinitis pigmentosa. Korean J Ophthalmol. 2009;23:164-168.

27. Burstedt MS, Monestam E. Self-reported quality of life in patients with retinitis pigmentosa and maculopathy of Bothnia type. Clin Ophthalmol. 2010;4:147-154.

28. Sugawara T, Sato E, Baba T, Hagiwara A, Tawada A, Yamamoto S. Relationship between vision-related quality of life and microperimetry-determined macular sensitivity in patients with retinitis pigmentosa. Jpn J Ophthalmol. 2011;55:643-646.

29. Reinhardt J. Effects of positive and negative support received and provided on adaptation to chronic visual impairment. Applied Dev Sci. 2001;5:76-85.

30. Cimarolli VR, Boerner K. Social support and well-being in adults who are visually impaired. J Vis Impair Blindness. 2005;99:521-534.

31. McIlvane JM, Reinhardt JP. Interactive effect of support from family and friends in visually impaired elders. $J$ Gerontol $B$ Psychol Sci Soc Sci. 2001;56:P374-P382.
32. Reinhardt JP, Boerner K, Horowitz A. Good to have but not to use: differential impact of perceived and received support on well-being. J Soc Pers Relat. 2006;23:117-129.

33. Nyman SR, Dibb B, Victor CR, Gosney MA. Emotional wellbeing and adjustment to vision loss in later life: a metasynthesis of qualitative studies. Disabil Rebabil. 2012;34:971981.

34. Cimarolli VR, Reinhardt JP, Horowitz A. Perceived overprotection: support gone bad? J Gerontol B Psychol Sci Soc Sci. 2006; 61:S18-S23.

35. Cimarolli VR, Boerner K, Reinhardt JP, Horowitz A. Perceived overprotection, instrumental support and rehabilitation use in elders with vision loss: a longitudinal perspective. Psychol Health. 2012;28:369-383.

36. Jang Y, Haley WE, Mortimer JA, Small BJ. Moderating effects of psychosocial attributes on the association between risk factors and disability in later life. Aging Ment Health. 2003;7:163-170.

37. O'Connor PM, Lamoureux EL, Keeffe JE. Predicting the need for low vision rehabilitation services. Br J Ophthalmol. 2008; 92:252-255.

38. Strawbridge WJ, Wallhagen MI, Shema SJ. Impact of spouse vision impairment on partner health and well-being: a longitudinal analysis of couples. J Gerontol B Psychol Sci Soc Sci. 2007;62:S315-S322.

39. Bambara JK, Owsley C, Wadley V, Martin R, Porter C, Dreer LE. Family caregiver social problem-solving abilities and adjustment to caring for a relative with vision loss. Invest Ophthalmol Vis Sci. 2009;50:1585-1592.

40. Bruijning JE. Development of the Dutch ICF Activity Inventory: Investigating and evaluating rebabilitation needs of visually impaired adults [PhD thesis]. Amsterdam, the Netherlands: Vrije Universiteit; 2013.

41. Department of Health. Certificate of vision impairment: explanatory notes for consultant ophthalmologists and hospital eye clinic staff. 2013. Available at: https://www.gov.uk/ government/uploads/system/uploads/attachment_data/file/ 213286/CVI-Explanatory-notes-in-DH-template.pdf. Accessed November 18, 2014.

42. Guerin E, Bouliotis G, King A. Visual impairment registration: evaluation of agreement among ophthalmologists. Eye. 2014; 28:808-813.

43. Linacre JM. A User's Guide to Winsteps/Ministep Rasch-Model Computer Programs. Program Manual 3.75.0. 2012. Available at: www.winsteps.com. Accessed: October 16, 2012.

44. Bond TG, Fox CM. Applying the Rasch Model: Fundamental Measurement in the Human Sciences. Mahwah: Lawrence Erlbaum Associates; 2001.

45. Andrich DA. A rating scale formulation for ordered response categories. Psychometrika. 1978;43:561-573.

46. Wright $\mathrm{BD}$, Linacre JM. Reasonable mean-square fit values. Rasch Measurement Transactions. 1994;8:370.

47. Gothwal VK, Wright TA, Lamoureux EL, Pesudovs K. Rasch analysis of visual function and quality of life questionnaires. Optom Vis Sci. 2009;86:1160-1168.

48. Marella M, Gothwal VK, Pesudovs K, Lamoureux EL. Validation of the Visual Disability Questionnaire (VDQ) in India. Optom Vis Sci. 2009;86:E826-E835.

49. Linacre JM. Dimensionality investigation - an example. Available at: http://www.winsteps.com/winman/ multidimensionality.htm. Accessed December 11, 2014.

50. Engel RJ, Welsh RL, Lewis LJ. Improving the well-being of vision-impaired older adults through orientation and mobility training and rehabilitation: an evaluation. RE:view. 2000;32: 67-76.

51. Kuyk T, Elliott JL, Wesley J, et al. Mobility function in older veterans improves after blind rehabilitation.J Rehabil Res Dev. 2004; $41: 337-346$. 
52. Clements B, Douglas G, Pavey S. Which factors affect the chances of paid employment for individuals with visual impairment in Britain? Work. 2011;39:21-30.

53. GOV.UK. Access to Work 2014. Available at: https://www.gov. uk/access-to-work/overview. Accessed November 24, 2014.

54. Tabrett D, Latham K. Factors influencing self-reported visionrelated activity limitation in the visually impaired. Invest Ophthalmol Vis Sci. 2011;52:5293-5302.

55. Latham K, Baranian M, Timmis MA, Pardhan S. Implementation of the Dutch Activity Inventory (D-AI) with people with retinitis pigmentosa. Paper presented at: European Academy of Optometry and Optics conference; May 15-18, 2014; Warsaw, Poland.

56. Nyman SR, Gosney MA, Victor CR. Emotional support to people with sight loss. London: Thomas Pocklington Trust; 2009.

57. Latham K. Evaluation of an emotional support service for the visually impaired. Optom Vis Sci. 2013;90:836-842.

58. Brody BL, Roch-Levecq A, Gamst AC, Maclean K, Kaplan RM, Brown SI. Self-management of age-related macular degeneration and quality of life: A randomized controlled trial. Arch Ophthalmol. 2002;120:1477-1483.
59. Ivanoff SD, Sonn U, Svensson E. A health education program for elderly persons with visual impairments and perceived security in the performance of daily occupations: a randomized study. Am J Occup Ther. 2002;56:322-330.

60. Packer TL, Girdler S, Boldy DP, Dhaliwal SS, Crowley M. Vision self-management for older adults: a pilot study. Disab Rehab. 2009;31:1353-1361.

61. Rees G, Keeffe JE, Hassell J, Larizza M, Lamoureux EL. A selfmanagement program for low vision: program overview and pilot evaluation. Disab Rebab. 2010;32:808-815.

62. Rees G, Saw C, Larizza M, Lamoureux E, Keeffe J. Should family and friends be involved in group-based rehabilitation programs for adults with low vision? Br J Vis Impair. 2007;25:155-168.

63. Bambara JK, Wadley VG, Owsley C, Martin R, Porter C, Dreer LE. Family functioning and low vision: a systematic review. $J$ Vis Impair Blindness. 2009;103:137-149.

64. Wolffsohn JS, Cochrane AL, Watt NA. Implementation methods for vision related quality of life questionnaires. $\mathrm{Br} \mathrm{J}$ Ophthalmol. 2000;84:1035-1040.

65. Bowling A. Mode of questionnaire administration can have serious effects on data quality. J Public Health. 2005;27:281291. 